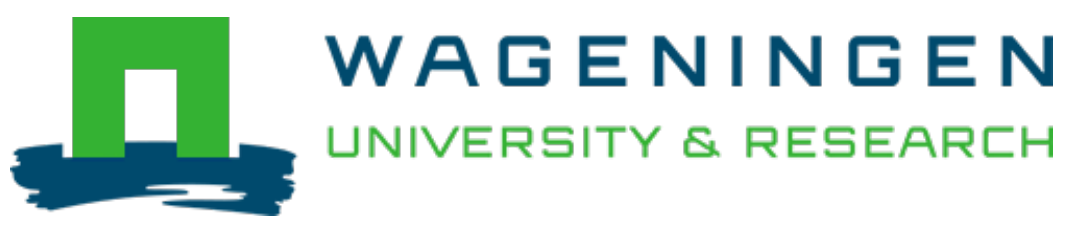

\title{
QTL identification for early blight resistance (Alternaria solani) in a Solanum lycopersicum x S. arcanum cross.
}

\author{
Theoretical and Applied Genetics \\ Chaerani, R.; Smulders, M.J.M.; Linden, C.G.; Vosman, B.; Stam, P. et al \\ https://doi.org/10.1007/s00122-006-0442-8
}

This article is made publicly available in the institutional repository of Wageningen University and Research, under the terms of article $25 \mathrm{fa}$ of the Dutch Copyright Act, also known as the Amendment Taverne. This has been done with explicit consent by the author.

Article 25 fa states that the author of a short scientific work funded either wholly or partially by Dutch public funds is entitled to make that work publicly available for no consideration following a reasonable period of time after the work was first published, provided that clear reference is made to the source of the first publication of the work.

This publication is distributed under The Association of Universities in the Netherlands (VSNU) 'Article $25 \mathrm{fa}$ implementation' project. In this project research outputs of researchers employed by Dutch Universities that comply with the legal requirements of Article $25 \mathrm{fa}$ of the Dutch Copyright Act are distributed online and free of cost or other barriers in institutional repositories. Research outputs are distributed six months after their first online publication in the original published version and with proper attribution to the source of the original publication.

You are permitted to download and use the publication for personal purposes. All rights remain with the author(s) and / or copyright owner(s) of this work. Any use of the publication or parts of it other than authorised under article $25 \mathrm{fa}$ of the Dutch Copyright act is prohibited. Wageningen University \& Research and the author(s) of this publication shall not be held responsible or liable for any damages resulting from your (re)use of this publication.

For questions regarding the public availability of this article please contact openscience.library@,wur.nl 


\title{
QTL identification for early blight resistance (Alternaria solani) in a Solanum lycopersicum $\times S$. arcanum cross
}

\author{
R. Chaerani - M. J. M. Smulders · C. G. van der Linden • \\ B. Vosman $\cdot$ P. Stam $\cdot$ R. E. Voorrips
}

Received: 24 November 2005/ Accepted: 21 October 2006/ Published online: 9 November 2006

(C) Springer-Verlag 2006

\begin{abstract}
Alternaria solani (Ellis and Martin) Sorauer, the causal agent of early blight (EB) disease, infects aerial parts of tomato at both seedling and adult plant stages. Resistant cultivars would facilitate a sustainable EB management. EB resistance is a quantitatively expressed character, a fact that has hampered effective breeding. In order to identify and estimate the effect of genes conditioning resistance to $\mathrm{EB}$, a quantitative trait loci (QTL) mapping study was performed in F2 and F3 populations derived from the cross between the susceptible Solanum lycopersicum (syn. Lycopersicon esculentum) cv. 'Solentos' and the resistant Solanum arcanum (syn. Lycopersicon peruvianum) LA2157 and genotyped with AFLP, microsatellite and SNP markers. Two evaluation criteria of resistance were used: measurements of EB lesion growth on the F2 plants in glasshouse tests and visual ratings of $\mathrm{EB}$ severity on foliage of the $\mathrm{F} 3$ lines in a
\end{abstract}

Communicated by T. Lübberstedt.

R. Chaerani - M. J. M. Smulders · C. G. van der Linden

B. Vosman · R. E. Voorrips $(\square)$

Plant Research International, P.O. Box 16,

6700 AA Wageningen, The Netherlands

e-mail: roeland.voorrips@wur.nl

P. Stam

Laboratory of Plant Breeding, Department of Plant

Sciences, Wageningen University, P.O. Box 386,

6700 AJ Wageningen, The Netherlands

Present Address:

R. Chaerani

Indonesian Center for Agricultural Biotechnology

and Genetic Resources Research and Development

(ICABIOGRAD), Jln. Tentara Pelajar no. 3A,

Bogor 16111, Indonesia field test. A total of six QTL regions were mapped on chromosomes 1, 2, 5-7, and 9 with LOD scores ranging from 3.4 to 17.5. Three EB QTL also confer resistance to stem lesions in the field, which has not been reported before. All QTL displayed significant additive gene action; in some cases a dominance effect was found. Additive $\times$ additive epistatic interactions were detected between one pair of QTL. For two QTL, the susceptible parent contributed resistance alleles to both EB and stem lesion resistance. Three of the QTL showed an effect in all tests despite methodological and environmental differences.

\section{Introduction}

Early blight (EB), incited by Alternaria solani (Ellis and Martin) Sorauer, is one of the most damaging diseases in many tomato production areas worldwide (Sherf and MacNab 1986). Symptoms caused by $A$. solani include collar rot on seedlings, leaf blight, stem lesions, and fruit rot. The disease is characterized by formation of dark, necrotic lesions with concentric rings giving a target-like appearance. Leaf blight, commonly referred to as $\mathrm{EB}$, is the most devastating of these symptoms. EB lesions first appear on the oldest leaves and spread upwards as the plants grow. Lesions enlarge and merge, resulting in early senescence and gradual defoliation. Complete defoliation may occur and leave fruits exposed to sun-scalding.

Early blight is prevalent in Indonesia and can cause yield losses as high as 23\% (Manohara 1971; Bos and Kartapradja 1977). Frequent applications of fungicides are necessary to control the disease; however, the 
incidence and severity of EB remain high due to heavy and frequent rainfall in the region. Even partial resistance would be an important improvement, because in combination with fungicides it could extend the intervals of fungicidal spray and therefore increase the net return of the growers.

Recently, a strong source of resistance to an Indonesian isolate of $A$. solani was identified in Solanum arcanum LA2157 (syn. Lycopersicon peruvianum LA2157) (R. Chaerani et al. submitted). In glasshouse tests, the average lesion size (LS) was only $1.4 \mathrm{~mm}^{2}$ compared to $23.0-108.0 \mathrm{~mm}^{2}$ on susceptible tomato accessions. S. arcanum LA2157 is known as resistance source to other pathogens, including bacterial canker (Sandbrink et al. 1995; Van Heusden et al. 1999), and root knot nematode (Veremis et al. 1999). The cross with Solanum lycopersicum (syn. L. esculentum) is difficult but possible through in vitro embryo rescue (Brüggemann et al. 1996).

Resistance may be difficult to transfer from wild species to cultivated tomato since it is accompanied by unacceptable horticultural traits including inferior fruit quality, late maturity, low-yielding ability, and indeterminate growth habit. Moreover, the quantitative expression and polygenic inheritance of EB resistance has limited the development of EB resistant cultivars using traditional breeding approaches.

Classical genetic studies revealed at least two genes with additive and dominance effects and epistatic interactions that confer resistance to EB symptoms (Barksdale and Stoner 1977; Nash and Gardner 1988; Maiero et al. 1990; Thirthamalappa and Lohithaswa 2000). According to Stancheva (1991) resistance to stem lesions was a quantitative trait conferred by additive and dominant genes with epistatic effects but the correlation with EB resistance was not investigated.

The identification of markers closely linked to resistance genes is of great benefit for breeding for two reasons. First, these markers allow selection based on marker genotype rather than resistant phenotype and secondly they enable minimizing unfavorable linkage drag. With the aid of a genetic linkage map, Foolad and co-workers (Foolad et al. 2002; Zhang et al. 2003) have identified and estimated the magnitude of quantitative trait loci (QTL) effects in a Solanum habrochaites (syn. L. hirsutum) resistance source using backcross populations. Using interval mapping and selective genotyping approaches, they identified fourteen QTL dispersed over 11 tomato chromosomes. Four QTL were potentially useful in marker assistedbreeding programs since they were stable across environments. It should be realized that such genes may not be effective in other regions of the world, where different $A$. solani populations may occur and other growth conditions prevail.

The current study is aimed at identification of QTL for EB resistance effective in Indonesia. Using F2 and F3 populations derived from a cross with $S$. arcanum LA2157 as the donor parent we have located EB resistance QTL, some of which also confer resistance to stem lesions. To our knowledge this is the first report of QTL for stem lesion resistance.

\section{Materials and methods}

Plant material

The mapping population was composed of $176 \mathrm{~F} 2$ individuals obtained from one embryo-rescued F1 plant of a cross between EB susceptible $S$. lycopersicum cv. 'Solentos' (De Ruiter Seeds) and an EB resistant $S$. arcanum LA2157 (Brüggemann et al. 1996). To allow replicated tests the F2 individuals were clonally propagated in vitro. Seeds were germinated on MS medium containing 1.0\% sucrose and $0.8 \%$ agar (Murashige and Skoog 1962) at $25^{\circ} \mathrm{C}$. After 2-3 weeks shoots were cut and transferred to MS medium supplemented with $2.0 \%$ sucrose and $0.4 \%$ agar. Clones were multiplied by transferring nodes to a fresh medium and cultured for 3-4 weeks. Prior to transfer to the glasshouse, shoots with two leaves were cut and root formation was induced on MS medium containing $1.5 \%$ sucrose, $0.8 \%$ agar, and $0.25 \mathrm{mg} \mathrm{l}^{-1}$ filter-sterilized IBA for 10-14 days. Rooted shoots were transferred to rock wool blocks in a glasshouse $\left(18-20^{\circ} \mathrm{C}\right)$ and allowed to acclimatize for 2 weeks. Plants were further grown for 4-5 weeks before inoculation with $A$. solani and received standard fertilization. Both 'Solentos' and LA2157, a moderately EB resistant (HRC86.329) and a susceptible (HRC90.145) genotype (Poysa and Tu 1996; Chaerani et al. 2006), which served as controls in resistance tests, were also clonally propagated in vitro. One set of F2 clones was allowed to self-pollinate to produce $\mathrm{F} 3$ seeds for use in a field test.

Early blight resistance evaluation

\section{F2 glasshouse test}

The complete evaluation of the F2 population (176 different genotypes) consisted of two series of four tests; each test was considered a block in the statistical analyses. In each test, one plant of 44 of the F2 clones, 
and two plants of each parent and control genotype were tested. Leaflets on intact plants were inoculated with $A$. solani isolate 60 , which was cultured and applied using the droplet test method (R. Chaerani et al. submitted). Abaxial surfaces of 12 terminal leaflets of four leaves were inoculated with spore droplets. Two droplets of $10 \mu \mathrm{l}$ of $4 \times 10^{3}$ spores $\mathrm{ml}^{-1}$ agar $0.1 \%$ were applied on each leaflet, making up a total of 24 inoculation sites on each plant. EB LS (length $\times$ width) was measured with a ruler on $4,7,10$, and 14 days after inoculation.

The area under the lesion expansion curve (AULEC) was calculated using the following formula:

AULEC $=\sum_{i=1}^{n-1}\left\{\left(\left[R_{i+1}+R_{i}\right] / 2\right) \times\left(t_{i+1}-t_{i}\right)\right\}$,

where $R_{i}$ is the LS at the $i$ th observation, $t_{i}$ is time (days after planting) at the $i$ th observation, and $n$ is the total number of observations. The AULEC values were then converted to the relative AULEC (RAULEC) by dividing each value by the period from the date of the first appearance of appreciable EB lesions, which was 2 days after inoculation, to the date of disease evaluation, and by the maximum LS recorded up to the final evaluation date. The theoretical maximum RAULEC value therefore is $100 \%$.

Lesions that did not grow beyond $1 \mathrm{~mm}^{2}$ were counted at 7 DPI. The percentage of these small lesions (PSmL) was strongly correlated with LS $\left(r^{2}=0.82\right)$.

\section{F3 field test}

Seeds were obtained from 156 F2 plants. Eight-weekold seedlings were transplanted in a field in Wanayasa (600 $\mathrm{m}$ altitude), West Java, Indonesia at a within-row distance of $0.35 \mathrm{~m}$ and a between-row distance of $0.9 \mathrm{~m}$ on raised beds $(30 \mathrm{~cm}$ high, $30 \mathrm{~cm}$ wide). The field test consisted of two blocks. Each block contained an 8-plant plot of each F3 family and the P1 ('Solentos'), and six 8-plant plots of each P2 (LA2157), HRC 90.145 and HRC 86.329. The field was bordered with cv. Ratna (East-West Seed Indonesia), a susceptible $S$. lycopersicum cultivar. Beds were covered with black polyethylene mulch to prevent the growth of weeds and watered with subsurface irrigation. Standard recommendations of fertilizer and growth regulator were applied. Insecticidal spray was done as necessary and a fungicide was applied once to prevent damping-off disease (Pythium spp.).
Each plant was artificially inoculated six times on December 13 and 20, 2004, January 3, 17, and 24, and February 7, 2005. Inocula were obtained from infected leaves, which were fragmented in a blender, sieved through cheesecloth and diluted ten times. At each inoculation about 30-60 l of inoculum was sprayed to the field.

Plants were individually rated for EB severity seven times at weekly interval from December 30, 2004 until February 9, 2005, on a scale of $0-7$, where $0=$ no symptoms, $1=$ trace to $1 \%, 2=2-5 \%, 3=6-10 \%$, $4=11-25 \%, 5=26-50 \%, 6=51-75 \%$, and $7=76-$ $100 \%$ of total foliage on middle third of canopy infected (Christ 1991). Stem infection was rated once on February 7 using a scale of $0-4$, where $0=$ no infection, $1=$ minute (up to $1 \mathrm{~mm}$ in diameter) and few lesions, $2=$ minute, scattered lesions, $3=$ slightly larger $(>1-$ $3 \mathrm{~mm}$ in diameter) and scattered lesions, and $4=$ many sunken, well-developed lesions, covering $>50 \%$ stem surface. Percentage of EB index (PEBI) and percentage of stem lesion index (PStLI) for each plot were calculated using the following formula:

Percentage of disease index $=$

$$
\frac{\text { sum of all ratings }}{\text { number of plants } \times \text { maximum rating grade }} \times 100 \text {. }
$$

The percentage of EB indices were used to calculate the area under the disease progress curve (AUDPC) analogous to the AULEC calculation and converted to the relative AUDPC (RAUDPC) using a similar method as for AULEC.

\section{DNA isolation and marker analysis}

For the SSR and SNP analysis, DNA was isolated from freeze-dried leaves using cell lysis and protein/polysaccharide precipitation methods according to Fulton et al. (1995) followed by DNA binding and elution using the DNAeasy ${ }^{\circledR}$ Plant Mini Kit column (Qiagen, Venlo, The Netherlands). DNA for AFLP analysis was prepared by Keygene N.V. from fresh, young leaves.

Thirty-six SSR markers were used in this population, including SSR11, SSR14, SSR22, SSR27, SSR32, SSR38, SSR40, SSR45, SSR52, SSR74, SSR86, SSR115, SSR135, SSR248, SSR320, SSR356 (Sol Genomics Network at www.sgn.cornell.edu; Table 1); LE20592, LECAB9, LECHI3, LECHSOD, LEHMG2A, LEILV1B, LESODB, LESSF, LEWIPIG (Smulders et al. 1997), LED10, LEE102 (Bredemeijer et al. 1998); TMS22, TMS48 (Areshchenkova and Ganal 1999); STRBCS1b (Sandbrink et al. 2000); EST245053, 
Table 1 Primer sequences for amplification of SSR and SNP markers

\begin{tabular}{|c|c|c|c|c|c|}
\hline \multicolumn{3}{|c|}{ SSR markers $^{\mathrm{a}}$} & \multicolumn{3}{|c|}{ SNP markers } \\
\hline \multicolumn{2}{|l|}{ Name } & \multirow{3}{*}{$\begin{array}{l}\text { Sequence }\left(5^{\prime}-3^{\prime}\right) \\
\text { CAAAAAAGAGTGAGGTAGTAGACA }\end{array}$} & \multicolumn{2}{|l|}{ Name } & \multirow{3}{*}{$\begin{array}{l}\text { Sequence }\left(5^{\prime}-3^{\prime}\right) \\
\text { TGTTTGTTTCAATTTATCAGTCATACT } \\
\text { CCGTTTCATTTTACGTGTCTTAGT }\end{array}$} \\
\hline LEB147 & F: & & Aco1 & F: & \\
\hline & $\mathrm{R}:$ & & & $\mathrm{R}:$ & \\
\hline \multirow[t]{2}{*}{ LED6 } & F: & GGAAGAACCCATAGATGATTA & ASR1 & F: & CATTCGTTTCAAAATAAGTGTTGTTG \\
\hline & $\mathrm{R}:$ & ACСТАTATAAAGTATAATAAACCCT & & $\mathrm{R}:$ & CAGCTGCTGCTATCTCTTCCTC \\
\hline \multirow[t]{2}{*}{ S75487 } & $\mathrm{F}:$ & TTTGTAAACATTACTTAAGAACACG & ASR3 & F: & CATGTCCTAAATTTTTGTGTCTAGTTAT \\
\hline & $\mathrm{R}:$ & TTTTGCTAATCCCTGATTGTA & & $\mathrm{R}:$ & TGTTCGCTTCAAATTATCTATCGT \\
\hline \multirow[t]{2}{*}{ SSR11 } & F: & CСTTCAATTGACСТСССТCA & Contig70 & F: & AGATTGACTGTGAAGGCGTCTTTGA \\
\hline & $\mathrm{R}:$ & GCATCTGGAAATTAGAGGCG & & $\mathrm{R}:$ & ACACCAGCTGGGATTTCATCTTCAT \\
\hline \multirow[t]{2}{*}{ SSR14 } & $\mathrm{F}:$ & TCTGCATCTGGTGAAGCAAG & CT259 & F: & GGCAACATCAATTGGCGTCTTTC \\
\hline & $\mathrm{R}:$ & CTGGATTGCCTGGTTGATTT & & $\mathrm{R}:$ & CCTGCTGATATTGGTTTTCCCTCAC \\
\hline \multirow[t]{2}{*}{ SSR22 } & F: & GATCGGCAGTAGGTGCTCTC & ID146 & F: & TTGGTGGTTCAAATCCTTATTG \\
\hline & $\mathrm{R}:$ & CAAGAAACACCCATATCCGC & & $\mathrm{R}:$ & ACACAACTTGTATCCGGAAAACAT \\
\hline \multirow[t]{2}{*}{ SSR27 } & F: & CCCAAATCAAGGTTTGTGGT & ID200 & F: & TTGCAAAGAAACAAGTGGACTAC \\
\hline & $\mathrm{R}:$ & TCAGATGCCACCACTCTCAG & & $\mathrm{R}:$ & ATTGTAATTGCTGGCTGAGTATTC \\
\hline \multirow[t]{2}{*}{ SSR32 } & F: & TGGAAAGAAGCAGTAGCATTG & ID222 & F: & TGTTGGAAAGAATTGGCTTTTGAATA \\
\hline & $\mathrm{R}:$ & CAACGAACATCCTCCGTTCT & & $\mathrm{R}:$ & TCCGGCTATAACTAGGGACATTGAA \\
\hline \multirow[t]{2}{*}{ SSR38 } & F: & GTTTCTATAGCTGAAACTCAACCTG & ID250 & F: & GGGGCCACAATCGTAAGAAAT \\
\hline & $\mathrm{R}:$ & GGGTTCATCAAATCTACCATCA & & $\mathrm{R}:$ & CCGAGCTAACGCATCAAAAAG \\
\hline \multirow[t]{2}{*}{ SSR40 } & F: & TGCAGGTATGTCTCACACCA & ID329 & F: & GCTGCAAATGAAGATAAAAGACC \\
\hline & $\mathrm{R}:$ & TTGCAAGAACACCTCCCTTT & & $\mathrm{R}:$ & GGAGCTTCATTCAATCTATGTTATCT \\
\hline \multirow[t]{2}{*}{ SSR45 } & F: & TGTATCCTGGTGGACCAATG & ID352 & F: & GGAGGATGCTGAGGTGTCAAGT \\
\hline & $\mathrm{R}:$ & TCCAAGTATCAGGCACACCA & & $\mathrm{R}:$ & CTGCGAGGTAGGGGTAAGGAC \\
\hline \multirow[t]{2}{*}{ SSR52 } & $\mathrm{F}:$ & TGATGGCAGCATCGTAGAAG & PRF1 & F: & ATGGCCATGGAGAAGAGACCTA \\
\hline & $\mathrm{R}:$ & GGTGCGAAGGGATTTACAGA & & $\mathrm{R}:$ & GGAAATGAGAGTTGGCATAAACAT \\
\hline \multirow[t]{2}{*}{ SSR74 } & F: & ACTCACCATGGCTGCTTCTT & RBCS3A & F: & TTGCTAGCAACGGTGGAAGAGTCA \\
\hline & R: & TTTCTTGAAGGGTCTTTCCC & & $\mathrm{R}:$ & TTCGGGCTTGTAAGCGATGAAAC \\
\hline \multirow[t]{2}{*}{ SSR86 } & $\mathrm{F}:$ & AGGGCAACAAATCCСТCTTT & SODCC & F: & GAAGCCAAAATTTATTTCAGAGAGG \\
\hline & $\mathrm{R}:$ & GGAGACGAGGCTGCTTACAC & & $\mathrm{R}:$ & CAAATCAGCTTGCCAATTAGTTCAG \\
\hline \multirow[t]{2}{*}{ SSR115 } & F: & CACCCTTTATTCAGATTCCTCT & & & \\
\hline & $\mathrm{R}:$ & ATTGAGGGTATGCAACAGCC & & & \\
\hline \multirow[t]{2}{*}{ SSR135 } & $\mathrm{F}:$ & TGATCGCTTGTGTCCACCTA & & & \\
\hline & $\mathrm{R}:$ & AAAGGAAGTGATGGAAAGCG & & & \\
\hline \multirow[t]{2}{*}{ SSR248 } & F: & GCATTCGCTGTAGCTCGTTT & & & \\
\hline & $\mathrm{R}:$ & GGGAGCTTCATCATAGTAACG & & & \\
\hline \multirow[t]{2}{*}{ SSR320 } & F: & ATGAGGCAATCTTCACCTGG & & & \\
\hline & $\mathrm{R}:$ & TTCAGCTGATAGTTCCTGCG & & & \\
\hline \multirow[t]{2}{*}{ SSR356 } & $\mathrm{F}:$ & ACCATCGAGGCTGCATAAAG & & & \\
\hline & $\mathrm{R}:$ & AACCATCCACTGCCTCAATC & & & \\
\hline
\end{tabular}

${ }^{a}$ Primers for SSR11-SSR356 were obtained from the Sol Genomics Network at www.sgn.cornell.edu; the other SSR and SNP primers in Table 1 were not published earlier

EST253712, EST259379 (Areshchenkova and Ganal 2002) and three new SSRs: LEB147, LED6, and S75487 (Table 1). PCR were done in 20- $\mu$ l volumes containing $10 \mathrm{ng}$ of genomic DNA, $0.2 \mu \mathrm{M}$ each of forward and reverse primers, $2 \mu \mathrm{l}$ of $10 \times$ Goldstar reaction buffer, $2.5 \mathrm{mM} \mathrm{MgCl}_{2}, 0.1 \mathrm{mM}$ each of dNTP, and $0.4 \mathrm{U}$ of GoldstarTaq DNA polymerase (Eurogentec, Maastricht, The Netherlands). DNA amplification was performed in a PTC-100 or PTC-200 thermocycler (MJ Research Inc., Waltham, MA, USA) using a profile of 3-min pre-denaturation at $94^{\circ} \mathrm{C}$ followed by $35-40$ cycles of $30 \mathrm{~s}$ at $94^{\circ} \mathrm{C}, 30 \mathrm{~s}$ at 50 or $55^{\circ} \mathrm{C}, 45 \mathrm{~s}$ at $72^{\circ} \mathrm{C}$, and finalized by a 10 -min extension at $72^{\circ} \mathrm{C}$. The PCR products were separated on 2.5$3.5 \%$ agarose gel $(\mathrm{w} / \mathrm{w})$ and visualized by ethidium bromide staining or separated on a $6 \%$ polyacrylamide gel and stained as described in the Promega Silver Staining Kit (Promega, Madison, WI, USA).

Fourteen SNP markers were developed from tomato RFLP probes or gene sequences present in public nucleotide databases (Table 1). SNP polymorphisms were detected using SNaPshot following the protocol of ABI Prism SNaPshot Multiplex Kit Protocol (Applied Biosystems, Foster City, CA, USA). PCR was performed in a $25-\mu 1$ volume consisting of $10 \mathrm{ng}$ DNA, $0.4 \mu \mathrm{M}$ each of forward and reverse primer, $2.5 \mu \mathrm{l}$ of $10 \times$ PCR buffer, $0.2 \mathrm{mM}$ each of dNTP, and $0.3 \mathrm{U}$ of HotStarTaq DNA polymerase (Qiagen). Amplification was carried out in a PTC-100 or PTC-200 thermal cycler, programmed for $15 \mathrm{~min}$ at $96^{\circ} \mathrm{C}$ for initial 
denaturation and 40 cycles consisting of $30 \mathrm{~s}$ at $96^{\circ} \mathrm{C}$, $45 \mathrm{~s}$ at $50^{\circ} \mathrm{C}$, and $90 \mathrm{~s}$ at $72^{\circ} \mathrm{C}$, followed by a final 10 -min extension at $72^{\circ} \mathrm{C}$. After amplification, PCR products were purified with SAP and ExoI for removal of dNTPs and primers. Up to ten different PCR products were pooled and single base-extended with SNaPshot primers and with fluorescent-labeled ddNTPs on a thermal cycler. Prior to analysis on an ABI 3700 sequencer (Applied Biosystems), samples were purified with SAP and ExoI to remove unincorporated ddNTPs. Data were analyzed using Genotyper 3.6 (PE Biosystems, Foster City, CA, USA).

AFLP analysis was performed by Keygene B.V. as previously described in Vos et al. (1995). The primer combinations used were P11M48, P11M50, P11M51, P11M60, P11M62, P13M47, P13M49, P13M61, P14M50, P14M51, P14M60, and P15M62. AFLP markers were scored codominantly.

\section{Linkage analysis}

The genetic map was constructed using JoinMap ${ }^{\circledR} 3.0$ (Van Ooijen and Voorrips 2001). Grouping of the markers was initially done with a minimum LOD-score of 3.0. The recombination threshold was set at 0.49 and the Kosambi mapping function was used to convert recombination frequencies into map distances.

\section{QTL mapping}

The MapQTL ${ }^{\circledR} 4.0$ software package (Van Ooijen et al. 2002) was used to identify QTL for all traits. First the interval mapping procedure was performed to identify the major QTL. For each trait a $1,000 \times$ permutation test was performed to identify the LOD threshold corresponding to a genome-wide false discovery rate of $5 \%(P<0.05)$. Markers with LOD scores exceeding the threshold were used as cofactors in multiple-QTL-model (MQM) mapping procedures. If new QTL were identified, the linked markers were added to the cofactor list and the analysis was repeated. If the LOD value of a marker dropped below the threshold in the new model, it was removed from the cofactor list and the MQM was rerun. This procedure was repeated until the cofactor list became stable. The final LOD scores and 2-LOD support intervals were determined using Restricted MQM.

\section{Statistical analysis}

All data were analyzed using GenStat ${ }^{\circledR} 6.0$ (Payne et al. 2002). The phenotypic data were transformed if necessary to achieve a normal error distribution.
ANOVA with unbalanced treatment structure and general ANOVA were used to analyze the F2 and F3 phenotypic data, respectively.

Main effects and epistatic interactions between all pairs of markers that were used as cofactors in QTL mapping were analyzed using general linear regression. Regression was performed by first fitting the main additive effect of each locus in the model. Loci with small and non-significant effects were dropped from the model and regressions were repeated, leaving only loci with significant effects at $P=0.05$. Next, dominance effects were fitted and new regressions were performed by dropping non-significant loci. Interactions between loci, starting from the lower to the higher order of interactions, were examined in a similar manner.

\section{Results}

\section{Linkage map}

For the construction of a genetic linkage map 176 F2 plants were genotyped with SSR and AFLP markers, whereas up to 171 plants were genotyped with SNP markers. Of 406 polymorphic markers, 389 (31 SSR, 14 SNP, and 344 AFLP) could be mapped on the 12 tomato chromosomes, resulting in a linkage map spanning 1,176 cM (average density 1 marker per $3 \mathrm{cM}$ ), which is similar to the $S$. lycopersicum $\times S$. pennellii (syn. L. pennellii) high-density map $(1,276 \mathrm{cM}$; Tanksley et al. 1992). Eighteen markers, which showed linkage to chromosomes 1,2, and 7 could not be placed in best positions with a 'jump threshold' of 5. Two markers were completely unlinked to all others. The number of markers mapped per chromosome ranged from 18 (chromosome 5) to 53 (chromosome 1). Linkage group length ranged from 71 (chromosome 9) to $143 \mathrm{cM}$ (chromosome 1). A high-marker density was observed in regions where centromeres have been mapped (Tanksley et al. 1992). The maps of chromosomes 5, 6, and 12 contained gaps longer than $20 \mathrm{cM}$. The order and placement of SSR and SNP markers were generally in good agreement with the $S$. lycopersicum $\times S$. pennellii reference map (Tanksley et al. 1992, Sol Genomics Network http://www.sgn.cornell.edu). The exceptions were CT259, SSR86, and ASR1, which according to the tomato reference map are on chromosomes 4,4 , and 1 , respectively, but were mapped on chromosomes 1, 3, 4 in our population. The orientation of linkage group 4 is unknown, since two SSR reference markers (TMS22 and EST259379) were originally co-mapped on $S$. lycopersicum $\times S$. pennellii 
map (Areshchenkova and Ganal 2002). These two markers were separated at $5.5 \mathrm{cM}$ distance in our population. The complete map can be obtained from the corresponding author.

\section{Distorted segregation}

A high proportion of the mapped markers (51\%) deviated significantly from the expected 1:2:1 segregation ratio for $\mathrm{F} 2$ generation at $P<0.05$. Distorted segregation was observed on all chromosomes. On chromosomes 1, 2, 4, and 7-9 more than $45 \%$ markers were skewed; this usually occurred only in part of the chromosome. The distortion on chromosome 1 was caused by a surplus of heterozygotes and $S$. arcanum homozygotes on the short arm of the chromosome. Markers on chromosome 9 displayed a higher frequency of heterozygotes, while distortions on chromosomes $2,4,7$, and 8 were caused by an excess of $S$. arcanum homozygotes.

\section{Phenotypic evaluation}

In order to achieve approximately normal error distributions of the traits scored in the F2 glasshouse tests, a $\log$ transformation was required for LS and RAULEC, whereas an arcsine transformation was applied to the PSmL data. The ANOVA analyses revealed significant block effects. For the F3 field data, EB assessment at $48 \mathrm{DAT}$ for PEBI and at $75 \mathrm{DAT}$ for RAUDPC were used, since the parents and control genotypes were most clearly distinguished at these dates. No transformation was required for PEBI and RAUDPC data, whereas an arcsine transformation was applied to the PStLI data.

All the resistance traits measured showed a continuous distribution with the population mean skewed toward resistance (Fig. 1). The phenotypic distributions of LS, RAULEC, PSmL, and PStLI showed a bimodal frequency distribution (Fig. 1). In the F2 data transgressive segregation occurred in both directions, whereas in the F3 data transgression was observed toward resistance only.

\section{QTL analysis}

\section{F2 glasshouse test}

Four QTL were identified from the glasshouse data on chromosomes 2, 5, 7, and 9 (Table 2; Fig. 2). The QTL for the three traits overlapped in all cases except that no significant QTL was found for PSmL on chromosome 5. This co-location is consistent with a higher correlation coefficient between LS and RAULEC $\left(r^{2}=0.95\right)$ than between PSmL and LS $\left(r^{2}=0.82\right)$ or between PSmL and RAULEC $\left(r^{2}=0.86\right)$.

For LS, the four QTL explained in total $40 \%$ of the phenotypic variance and individual QTL accounted for $8.1-13.3 \%$ of the phenotypic variance. For RAULEC each QTL explained $6.9-15.2 \%$ of the phenotypic variance, whereas each QTL for PSmL accounted for $8.6-16.0 \%$ of the phenotypic variance. The QTL on chromosome 7 was the most important in explaining the phenotypic variation, regardless the type of traits measured. Beneficial alleles were contributed by the susceptible parent at the QTL on chromosomes 2 and 7.

All QTL exhibited significant additive gene action $(P<0.05$ or $<0.001)$, but dominant effects were also displayed by the QTL on chromosome 2 for PSmL and PStLI $(P<0.05)$, the QTL on chromosome 7 for LS $(P<0.001)$ and PSmL $(P<0.05)$, and the QTL on chromosome 9 for LS and RAULEC $(P<0.001)$. No between-locus interactions were found for the QTL detected in the glasshouse.

\section{F3 field test}

One main QTL on chromosome 9 and two QTL with smaller effects on chromosomes 2 and 6 were identified for PEBI (Table 2; Fig. 2). The LOD value of the QTL on chromosome 6 was below the threshold value (3.67), but it was included in the analyses as it was also associated with RAUDPC (see below). When used as cofactor, the marker at this QTL increased the LOD value of the main QTL from 5.91 to 6.57 and the LOD of the other minor QTL from 3.32 to 3.68.

Five QTL for RAUDPC were identified on chromosomes 1, 2, 5, 6, and 9. Collectively these QTL explained $49 \%$ of the phenotypic variance and they all showed additive gene action $(P<0.001)$. A proportion of more than $10 \%$ of the phenotypic variances was explained by the QTL on chromosomes 2, 5, 6, and 9 . Except for the QTL on chromosome 2, all QTL inherited the allele for resistance from the resistant parent. The QTL on chromosomes 2, 6, and 9 were also associated with PEBI. This is in agreement with a high correlation between the phenotypic values of the two disease traits $\left(r^{2}=0.80\right)$.

Resistance to stem lesions was associated with three QTL on chromosomes 2, 5, and 9. The QTL on chromosome 9 was the most important for resistance to stem lesions since by itself it explained $35 \%$ of the phenotypic variance. The 2-LOD support intervals of the stem lesion QTL partly or completely overlapped those of three QTL for RAUDPC or PEBI. 

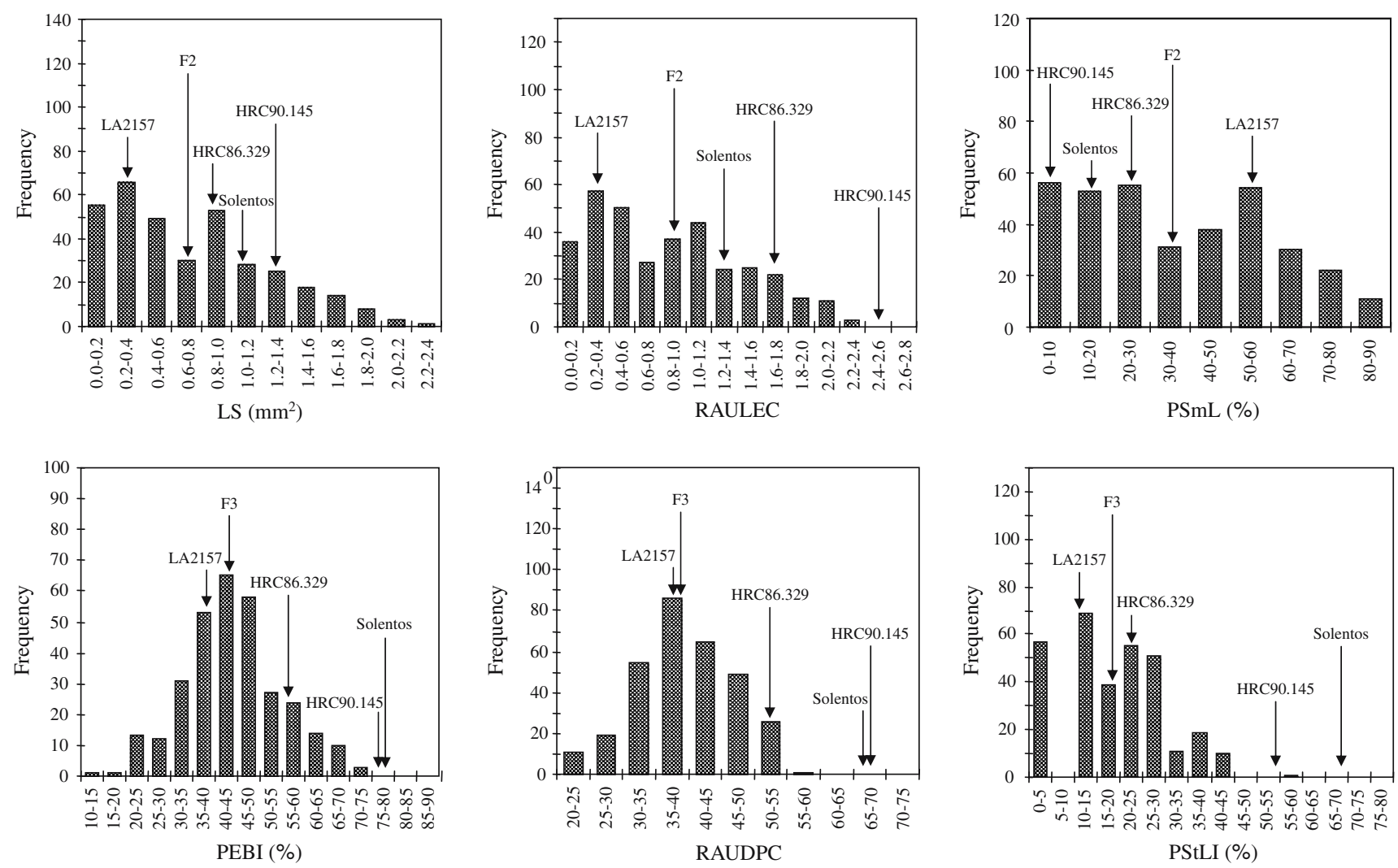

Fig. 1 Frequency distribution for lesion size $(L S)$, percentage of small lesions $(P S m L)$, and relative area under the lesion expansion curve $(R A U L E C)$ in an $\mathrm{F} 2$ population of the cross Solanum lycopersicum 'Solentos' $\times$ Solanum arcanum LA2157, and for percentage of early blight index $(P E B I)$, relative area under the disease progress curve (RAUDPC), and percentage of stem lesion index $(P s t L I)$ in a population of $\mathrm{F} 3$ lines derived

Irrespective of the type of disease syndrome and the trait measured, the QTL on chromosome 9 was the most important in the field. For each trait measured, it explained the largest proportion of the phenotypic variance.

Additive genetic effects were prevalent for the QTL detected in the field, while the QTL on chromosome 9 also displayed a dominant genetic effect $(P<0.001)$ on stem lesion resistance. Digenic epistatic interactions of the type additive $\times$ additive $(P<0.05)$ were found for RAUDPC between the QTL on chromosomes 2 and 9.

\section{Discussion}

\section{Linkage analysis}

Deviation from the expected segregation ratio is a common feature of tomato interspecific crosses, often with the extent of skewness being higher on wider crosses. A skewness rate of $50 \%$ was reported in a from that F2. The F2 population was tested in a glasshouse in The Netherlands with a single Alternaria solani isolate; the F3 population in a field in Indonesia with mixed field isolates. The means of the parents and the F2 or F3 are indicated, as well as those of two reference tomato lines HRC86.329 (moderately resistant) and HRC90.145 (susceptible)

S. lycopersicum $\times S$. cheesmaniae (syn. L. cheesmanii) F2 population (Paterson et al. 1991), and up to $80 \%$ in a S. lycopersicum $\times S$. pennellii $\mathrm{F} 2$ population (De Vicente and Tanksley 1993). Less skewed segregation (8$10 \%$ ) was exhibited in crosses with $S$. pimpinellifolium (syn. L. pimpinellifolium), a species closely related with the cultivated tomato (Grandillo and Tanksley 1996; Chen and Foolad 1999). A distortion rate (55\%) similar to our result was previously reported by Van Heusden et al. (1999) using a different subset of F2 progeny from the same cross with $S$. arcanum LA2157. The aberrant segregation on chromosomes 2, 4, 7, and 8 toward $S$. arcanum alleles was also previously reported by Van Heusden et al. (1999). Additionally, an excess in heterozygotes was observed on chromosome 9 , as was also observed by Fulton et al. (1997) in a cross with $S$. arcanum LA1708 (syn. L. peruvianum LA1708). In our population, QTL for EB resistance were observed both in regions with skewed segregations (chromosomes 2, 6, 7 , and 9) and in regions without skewed segregation (chromosomes 1 and 5). 
Table 2 Quantitative trait loci for early blight and stem lesion resistance identified by multiple-QTL-models mapping ( $M Q M)$ method

\begin{tabular}{|c|c|c|c|c|c|c|c|c|c|}
\hline Chr & Trait & Test & Cofactor & Position (cM) & Coverage $(\mathrm{cM})^{\mathrm{a}}$ & LOD score ${ }^{b}$ & $\% \operatorname{expl}$ & Add & Dom \\
\hline 1 & RAUDPC & F3, field & P14M60-276P & 138 & 31 & 4.07 & 6.8 & $2.26 * * *$ & -0.50 \\
\hline 2 & LS & F2, glasshouse & P11M48-082E & 34 & 42 & 5.58 & 9.5 & $-0.19 * * *$ & 0.09 \\
\hline 2 & RAULEC & F2, glasshouse & P15M62-073P & 42 & 42 & 4.19 & 7.2 & $-0.24 * * *$ & 0.12 \\
\hline 2 & $\mathrm{PSmL}^{\mathrm{c}}$ & F2, glasshouse & P13M49-435E & 36 & 42 & 5.42 & 10.3 & $9.45 * * *$ & $-8.08 *$ \\
\hline 2 & PEBI & F3, field & P11M60-276E & 86 & 18 & 3.36 & 7.6 & $-3.64 * * *$ & -0.69 \\
\hline 2 & RAUDPC & F3, field & P14M51-146E & 78 & 18 & 8.99 & 16.2 & $-4.23 * * *$ & 1.00 \\
\hline 2 & PStLI & F3, field & P13M49-352P & 61 & 35 & 4.00 & 4.8 & $-3.52 * *$ & $1.99 *$ \\
\hline 5 & LS & F2, glasshouse & P14M51-055P & 58 & 36 & 4.75 & 8.1 & $0.15^{* * *}$ & -0.01 \\
\hline 5 & RAULEC & $\mathrm{F} 2$, glasshouse & P14M51-055P & 58 & 41 & 3.95 & 6.9 & $0.21 * * *$ & -0.03 \\
\hline 5 & RAUDPC & F3, field & P14M51-055P & 58 & 39 & 6.14 & 10.5 & $2.92 * * *$ & 0.34 \\
\hline 5 & PStLI & F3, field & P14M50-537P & 55 & 75 & 4.63 & 7.5 & $3.21 * * *$ & -1.01 \\
\hline 6 & PEBI & F3, field & P13M49-231E & 51 & 36 & 3.68 & 8.2 & $3.76^{* *}$ & -2.03 \\
\hline 6 & RAUDPC & F3, field & P11M48-266E & 29 & 21 & 6.26 & 10.8 & $3.42 * * *$ & 0.23 \\
\hline 7 & LS & F2, glasshouse & P15M62-349P & 36 & 33 & 7.54 & 13.3 & $-0.22 * * *$ & $0.08^{* * *}$ \\
\hline 7 & RAULEC & F2, glasshouse & P15M62-349P & 36 & 33 & 8.26 & 15.2 & $-0.35^{* * *}$ & 0.16 \\
\hline 7 & $\mathrm{PSmL}^{\mathrm{c}}$ & F2, glasshouse & P15M62-349P & 36 & 30 & 8.09 & 16.0 & $11.32 * * *$ & $-5.03 *$ \\
\hline 9 & LS & $\mathrm{F} 2$, glasshouse & P14M50-081E & 53 & 31 & 4.87 & 8.2 & $0.17 * * *$ & $-0.14 * * *$ \\
\hline 9 & RAULEC & $\mathrm{F} 2$, glasshouse & P14M50-081E & 53 & 31 & 5.23 & 9.2 & $0.27 * * *$ & $-0.18 * * *$ \\
\hline 9 & $\mathrm{PSmL}^{\mathrm{c}}$ & $\mathrm{F} 2$, glasshouse & P11M48-065E & 41 & 22 & 4.61 & 8.6 & $-8.56^{* * *}$ & 0.92 \\
\hline 9 & PEBI & F3, field & P11M60-109P & 25 & 23 & 6.57 & 15.4 & $5.32 * * *$ & -0.41 \\
\hline 9 & RAUDPC & F3, field & P11M60-109P & 25 & 23 & 8.70 & 15.5 & $3.50 * * *$ & 1.35 \\
\hline 9 & PStLI & F3, field & P14M50-072P & 33 & 14 & 17.48 & 34.5 & $7.01 * * *$ & $-3.93 * *$ \\
\hline
\end{tabular}

$C h r$ chromosome number, \% expl. explained part of the phenotypic variance, $A d d$ additive effect, Dom dominance effect, $L S$ lesion size $\left(\mathrm{mm}^{2}\right), P S m L$ percentage of small lesions, $P E B I$ percentage of early blight index, RAUDPC relative area under the disease progress curve, RAULEC relative area under the lesion expansion curve, PstLI percentage of stem lesion index

${ }^{a}$ Based on 2-LOD support interval obtained from restricted MQM mapping; distance between flanking markers

b The LOD thresholds obtained from $1,000 \times$ permutation tests for a genome wide significance $(P<0.05)$ were $3.70,3.54,3.51,3.67$, 3.67, and 3.69 for LS, PSmL, RAULEC, PEBI, RAUDPC, and PStLI, respectively

c The QTL effects of PSmL are opposite to those for all other traits, as a high value for PSmL indicates resistance while a high value of the other traits indicates susceptibility

$* P<0.05$, according to $t$-test

$* * P<0.01$, according to $t$-test

$* * * P<0.001$, according to $t$-test

QTL analysis

We assessed EB resistance at the single plant level in the $\mathrm{F} 2$ population in glasshouse tests using inoculation with a single isolate and compared these data to the F3 data from a field test under artificial inoculations with mixed field isolates. Six EB QTL were detected, if we consider QTL for different traits of which the 2-LOD support intervals touch or overlap as the same EB QTL. Two of these (the QTL on chromosomes 2 and 7) inherited the resistant allele from the susceptible parent. This is not uncommon and has been reported in many plant species (e.g., Young et al. 1993; Lefebvre and Palloix 1996; Pilet et al. 1998). For EB resistance in tomato, Zhang et al. (2003) also detected a QTL on chromosome 3 for which the resistance allele was inherited from the susceptible parent. The presence of QTL with effects opposite to those predicted by the parents may be responsible for the occurrence of individuals with transgressive phenotypes (De Vicente and Tanksley 1993; Dirlewanger et al. 1994).

Notwithstanding the differences in experimental techniques (pathogen isolates, inoculation method, and resistance assessment criteria) and environmental conditions between the disease tests, we detected three EB QTL in the glasshouse (chromosomes 2, 5, and 9), which coincided with QTL for resistance traits in the field. Two QTL were detected with a significant effect only on the field-test trait RAUDPC on chromosomes 1 and 6, with the second also having an effect on PEBI. One QTL on chromosome 7 was the major QTL affecting all glasshouse test traits, while it showed no effect on the field test traits. Especially the QTL on chromosome 9 is interesting: it is the major QTL detected for all traits in the F3 field test, and it is also an important QTL in the F2 glasshouse tests. 
Fig. 2 Map positions of QTL for resistance to leaf and stem lesion of EB disease depicted on a skeletal map based on an F2 population of the cross Solanum lycopersicum cv. 'Solentos' $\times$ Solanum arcanum LA2157. QTL are represented by bars covering 2-LOD support intervals obtained by restricted multiple-QTL-method (RMQM) mapping. Triangles indicate the position of the markers used as co-factor; solid triangles indicate that the resistant alleles were contributed by the susceptible parent ('Solentos'). Lesion size $(L S)$, the relative area under the lesion expansion curve (RAULEC), and percentage of small lesions $(P S m L)$ were assessed in the $\mathrm{F} 2$ population inoculated with a single Alternaria solani isolate in a glasshouse in The Netherlands; percentage of EB index (PEBI), the relative area under the disease progress curve (RAUDPC), and percentage of stem lesion index (PstLI) were assessed in the F3 population inoculated with mixed field isolates in a field in Indonesia
1

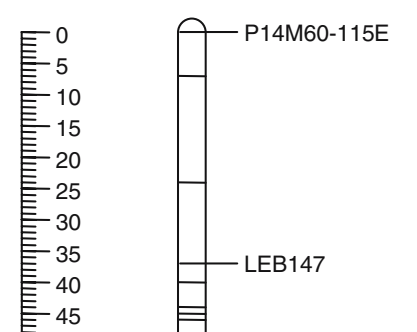

監50

㱔 50

臨 60

監75

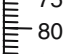

晨 85

監95

臨 100

監 110

115

㭋 120

作 125

铸 135

監 140

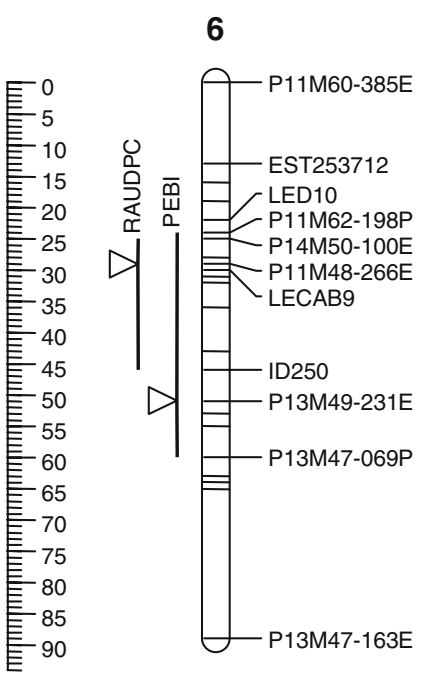

2

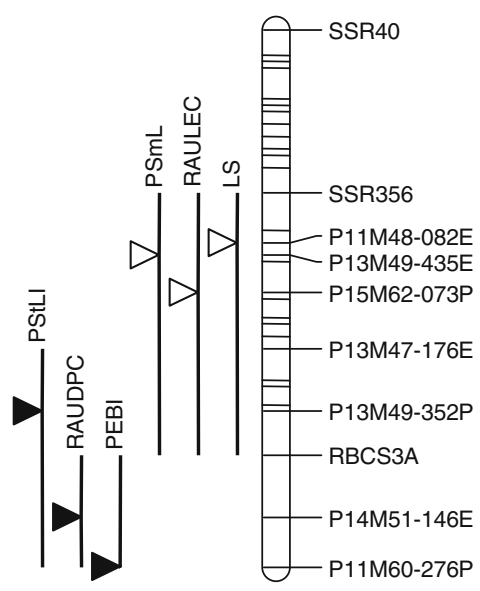

5

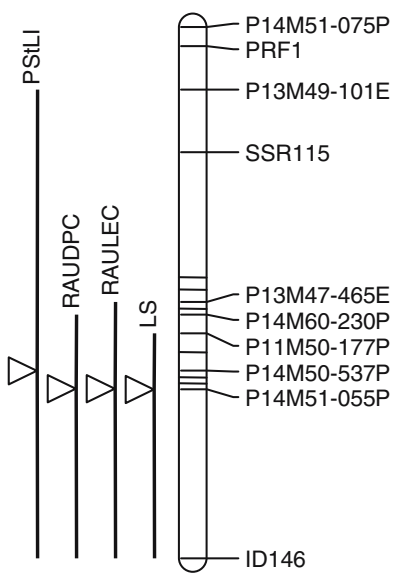

7

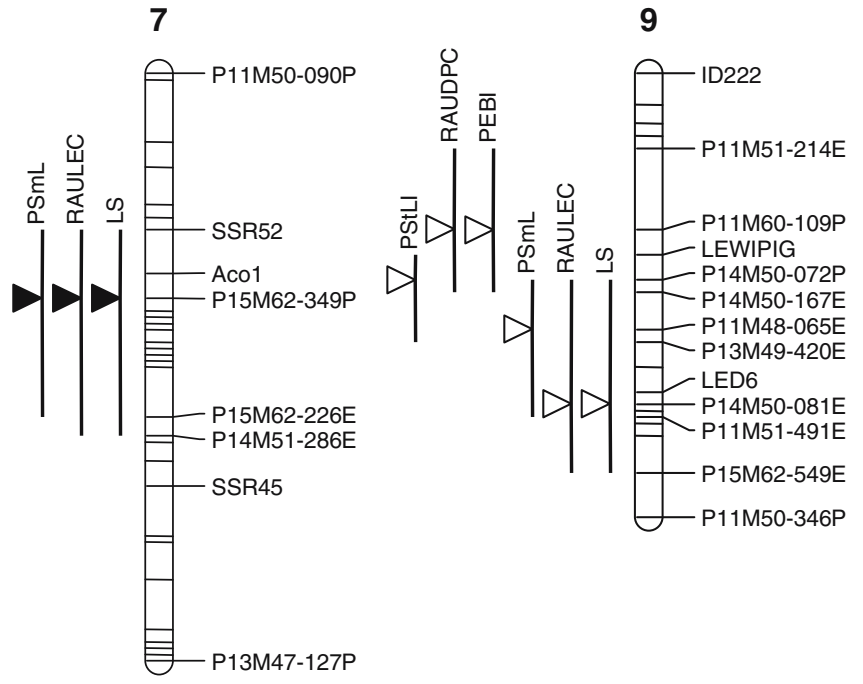

Plant conditions, including developmental stage and physiological state may affect the expression of QTL for resistance. Young et al. (1993) observed two QTL for resistance to powdery mildew in mungbean, which were significant at 65 days after planting and detected a different QTL at 85 days after planting. In our study, the QTL on chromosome 7 showed an effect in glasshouse tests with young plants (56-63 days after planting), whereas the QTL on chromosomes 1 and 6 were only effective in the field at later plant stage (90110 days after sowing). The QTL on chromosome 7, which inherited the favorable alleles from the suscep- tible parent, might not have a true effect on EB resistance. As the susceptible parent is a cultivated, semi-determinate $S$. lycopersicum variety and much better adapted to the glasshouse test environment than the resistant, indeterminate $S$. arcanum parent, this suggests that the QTL on chromosome 7 may affect the condition of the plants in the glasshouse rather than the resistance itself. Thus, plants carrying the S. lycopersicum allele would in general be more vigorous and therefore better able to withstand infection, which overshadows the effect of their genotype at the 'true' resistance QTL. The fact that well-fertilized plants are 
more resistant than plants starved for nutrients and that young plant generally show more apparent resistance to EB than older plant (Rotem 1994) support the notion that plant condition can affect EB resistance. Whether this speculation is true or not, the QTL on chromosome 7 is not an interesting target for breeders, as it does not show an effect on EB severity in the field.

The detection of common QTL at different experimental locations may be hampered by genotype $\times$ environment or genotype $\times$ isolate interactions as was observed in some studies, e.g., by Lübberstedt et al. (1999). We do not preclude the presence of such interactions in EB resistance that might further explain the discrepancy between the F2 glasshouse and F3 field tests; however, such interactions could not be determined in this study. In the two environments different isolates were used, so that the effects of the isolates and experimental conditions were confounded.

Comparison with classical genetic and molecular mapping studies of EB resistance

The current research is the first genetic study of EB resistance using $S$. arcanum LA2157 as a donor parent. In a glasshouse experiment where LA2157 was tested together with several well-known resistant accessions, using the same Indonesian $A$. solani isolate and the same experimental conditions as used in the F2 glasshouse test, LA2157 formed lesions of similar size as $S$. peruvianum $\mathrm{PE} 44$ and significantly smaller lesions than all other accessions including $S$. lycopersicum NCEBR1 to NC-EBR6, $S$. peruvianum PE33, and $S$. habrochaites PE36 (Chaerani et al. 2006). Our results concur with previous classical genetic and molecular mapping studies using S. habrochaites (syn. L. hirsutum) or derived materials and $S$. pimpinellifolium, which indicate that EB resistance is under polygenic control. Additive genetic effects were predominant (Nash and Gardner 1988; Maiero et al. 1990; Thirthamalappa and Lohithaswa 2000; Foolad et al. 2002; Zhang et al. 2003); in some cases also dominant effects (Nash and Gardner 1988; Thirthamalappa and Lohithaswa 2000) as well as epistatic interactions (Nash and Gardner 1988; Maiero et al. 1990; Thirthamalappa and Lohithaswa 2000) were observed.

It has been observed that EB resistance tends to be associated with indeterminate growth habit, selfincompatibility, low yield and lateness (Nash and Gardner 1988; Foolad et al. 2002). However it is not clear whether this association is due to a direct effect of these traits on EB development, to (other) pleiotropic effects of resistance genes or to linkage drag, In our study, the F2 plants were tested at a juvenile stage where direct effects of these traits on resistance are unlikely. The F3 plants were tested between 10 and 16 weeks after sowing, during which period fruit production started but the plants did not completely mature. Even with this difference in development we observed substantial overlap between the QTL identified in the F2 and the F3 generation, which suggests that the effects of

Table 3 Mean values for resistance parameters of F2 plants and the derived F3 lines based on the QTL genotypes on chromosomes 2 and 9

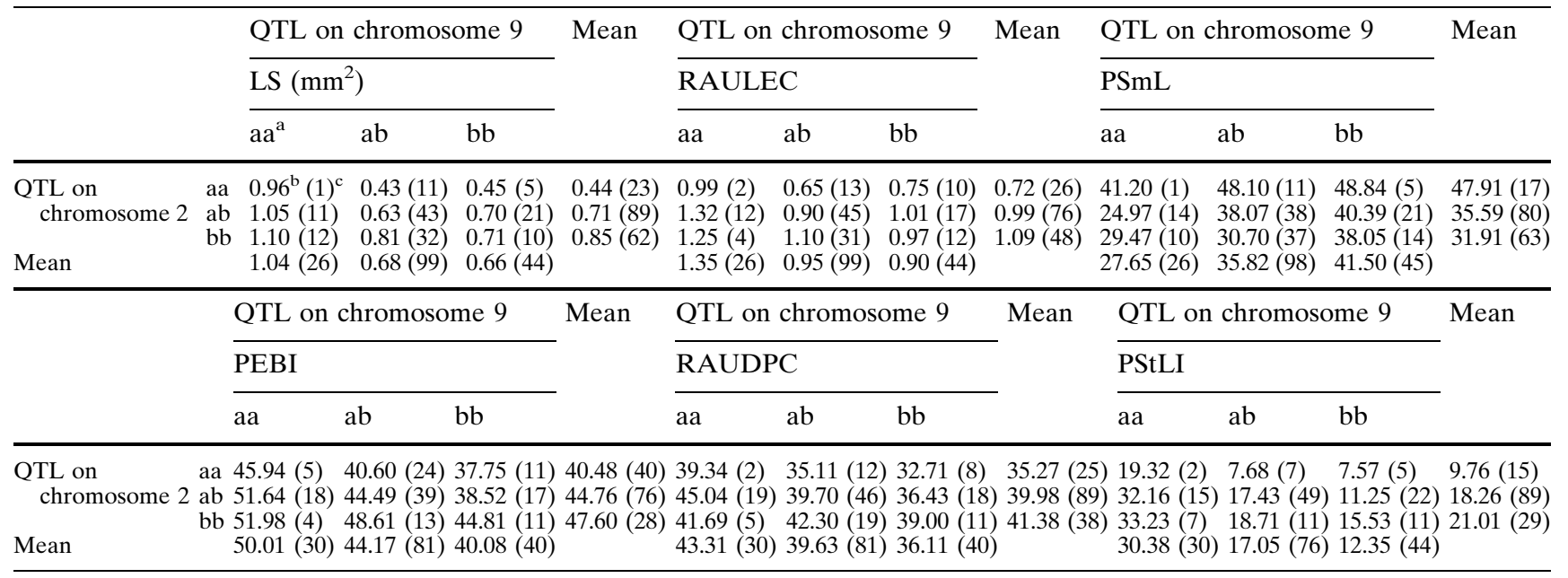

The QTL on chromosome 2 inherited the resistant alleles from the susceptible parent 'Solentos'

a aa = homozygous 'Solentos', ab = heterozygous 'Solentos'/LA2157, bb = homozygous LA2157

b Values are $\log (x+1)$ transformation for lesion size $(L S)$ and relative area under the lesion expansion curve $(R A U L E C)$ and arcsine $\sqrt{ }(x / 100)$ transformation for percentage of small lesions $(P S m L)$, and percentage of stem lesion index (PStLI)

${ }^{\mathrm{c}}$ Figures in parentheses are the number of F2 plants or F3 lines 
the mentioned plant traits, if present, were not so large as to obscure the segregation of true resistance.

Although we used a different resistance source, the 2-LOD support intervals of our QTL overlapped with the QTL regions detected by Foolad et al. (2002) and Zhang et al. (2003), except for the QTL on chromosome 7 which was not detected in their studies. The smaller number of QTL detected in our study may be due to a higher LOD threshold employed (3.5-3.7 depending on the trait) compared to the previous mapping study using an $S$. habrochaites source which used a LOD threshold of 2.4 (Foolad et al. 2002). Both studies revealed no major QTL for EB resistance, but rather showed that resistance is controlled by several QTL with small effects: 7-16\% explained variance in our study, and $4-22 \%$ in Foolad et al. (2002). The number of QTL (7) detected by Zhang et al. (2003) using selective genotyping on a backcross population with $S$. habrochaites as donor was similar to the number of QTL (6) we identified. A larger mapping population and more replications could possibly uncover more QTL for EB resistance, but probably no major QTL will be found.

Previous studies showed that stem lesion resistance was found in the same sources as EB resistance but the genetic relationship was not investigated (Barksdale and Stoner 1973, 1977; Stancheva et al. 1991a, b). In the present study, three EB resistance QTL coincided with stem lesion resistance QTL; one QTL on chromosome 9 even had a major effect on the stem lesion resistance $(35 \%)$.

\section{Breeding implications}

For breeding purposes QTL with large additive effects, which are stable across environments and which do not depend on epistatic interactions, are most desirable. QTL, which meet these criteria perfectly were not found in the current study. Nevertheless, it would be useful for breeders to make use of the QTL on chromosomes 2 and 9 as they are effective in both environments and are the most important according to the field test results. Genotypes homozygous for the 'Solentos' allele at the favorable QTL allele on chromosome 2 or for the LA2157 allele at the QTL on chromosome 9 showed enhanced resistance as measured by different parameters (Table 3 ). A further increase in resistance was generally observed in the double homozygotes. It is possible that the QTL on chromosome 2 is already present in most tomato material; in that case only the QTL on chromosome 9 would have to be introgressed. For introgression purposes a more precise determination of the QTL posi- tions will be needed. This could be achieved through the development of a population of plants or lines, each containing parts of the $S$. arcanum QTL regions in a cultivated tomato background.

Acknowledgments We thank Gerda Uenk, Hanneke van der Schoot and Wendy van 't Westende for help and advice in the marker analyses; Paul Arens for developing SSR primers; Dirk Budding and Remmelt Groenwold for assistance with in vitro plant culture; Daan Jaspers and Geurt Versteeg for plant care in the glasshouse. Nurul Hidayati, Vita Anggraini and Sularno of East-West Seed Indonesia are gratefully acknowledged for conducting the field trial, and the companies Enza Zaden, Syngenta Seeds and Nunhems Zaden for co-funding part of the SNP development and for permission to publish. R.C. was supported by the Royal Netherlands Academy of Arts and Sciences in the framework of the Scientific Programme Indonesia-The Netherlands.

\section{References}

Areshchenkova T, Ganal MW (1999) Long tomato microsatellites are predominantly associated with centromeric regions. Genome 42:536-544

Areshchenkova T, Ganal MW (2002) Comparative analysis of polymorphisms and chromosomal location of tomato microsatellite markers isolated from different sources. Theor Appl Genet 104:229-235

Barksdale TH, Stoner AK (1973) Segregation for horizontal resistance to tomato early blight. Plant Dis Rep 57:964-965

Barksdale TH, Stoner AK (1977) A study of the inheritance of tomato early blight resistance. Plant Dis Rep 61:63-65

Bos G, Kartapradja R (1977) Tomato variety trials on Java with emphasis on yield potential, adaptability to environment and tolerance to pests and diseases. Bull Penelitian Hortikultura 5:93-113

Bredemeijer GMM, Arens P, Wouters D, Visser D, Vosman B (1998) The use of semi-automated fluorescent microsatellite analysis for tomato cultivar identification. Theor Appl Genet 97:584-590

Brüggemann W, Linger P, Wenner A, Koornneef M (1996) Improvement of post-chilling photosynthesis in tomato by sexual hybridization with a Lycopersicon peruvianum line from elevated altitude. Adv Hort Sci 10:215-218

Chaerani R, Groenwold R, Stam P, Voorrips RE (2006) Assessment of early blight (Alternaria solani) resistance in tomato using a droplet inoculation method. J Gen Plant Pathol (in press)

Chen FQ, Foolad MR (1999) A molecular linkage map of tomato based on a cross between Lycopersicon esculentum and L. pimpinellifolium and its comparison with other molecular maps of tomato. Genome 42:94-103

Christ BJ (1991) Effect of disease assessment method on ranking potato cultivars for resistance to early blight. Plant Dis 75:353-356

De Vicente MC, Tanksley SD (1993) QTL analysis of transgressive segregation in an interspecific tomato cross. Genetics 134:585-596

Dirlewanger E, Isaac PG, Ranades S, Belajouza M, Cousin R, de Vienne D (1994) Restriction fragment length polymorphism analysis of loci associated with disease resistance genes and developmental traits in Pisum sativum L. Theor Appl Genet 88:17-27 
Foolad MR, Zhang LP, Khan AA, Niño-Liu D, Lin GY (2002) Identification of QTLs for early blight (Alternaria solani) resistance in tomato using backcross populations of a Lycopersicon esculentum $\times$ Lycopersion hirsutum cross. Theor Appl Genet 104:945-958

Fulton TM, Chunwongse J, Tanksley SD (1995) Microprep protocol for extraction of DNA from tomato and other herbaceous plants. Plant Mol Biol Rep 13:207-209

Fulton TM, Nelson JC, Tanksley SD (1997) Introgression and DNA marker analysis of Lycopersicon peruvianum, a wild relative of the cultivated tomato, into Lycopersicon esculentum, followed through three successive backcross generations. Theor Appl Genet 95:895-902

Grandillo S, Tanksley SD (1996) Genetic analysis of RFLPs, GATA microsatellites and RAPDs in a cross between $L$. esculentum and L. pimpinellifolium. Theor Appl Genet 92:957-965

Lefebvre V, Palloix A (1996) Both epistatic and additive effects of QTL are involved in polygenic induced resistance to disease: a case study, the interaction pepper-Phytophthora capsici Leonian. Theor Appl Genet 93:503-511

Lübberstedt T, Xia XC, Tan G, Liu X, Melchinger AE (1999) QTL mapping of resistance to Sporisorium reiliana in maize. Theor Appl Genet 99:593-598

Maiero M, Ng TJ, Barksdale TH (1990) Genetic resistance to early blight in tomato breeding lines. HortScience 25:344346

Manohara D (1971) Penyakit-penyakit pada tanaman famili Solanaceae di Lembang dan Pacet. Fakultas Pertanian Institut Pertanian Bogor, Bogor, p.33

Murashige T, Skoog F (1962) A revised medium for rapid growth and bioassays with tobacco tissue cultures. Physiol Plant 15:473-497

Nash AF, Gardner RG (1988) Heritability of tomato early blight resistance derived from Lycopersicon hirsutum PI 126445. J Am Soc Hort Sci 113:264-268

Paterson AH, Damon S, Hewitt JD, Zamir D, Rabinowitch HD, Lincoln SE, Tanksley SD (1991) Mendelian factors underlying quantitative traits in tomato: comparison across species, generations, and environments. Genetics 127:181197

Payne RW, Harding SA, Murray DA, Soutar DM, Baird DB, Welham SJ, Kane AF, Gilmour AR, Thompson R, Webster R, Wilson GT (2002) GenStat ${ }^{\circledR}$ for Windows ${ }^{\mathrm{TM}}$, 6th edn. VSN International, Oxford

Pilet ML, Delourme R, Foisset N, Renard M (1998) Identification of loci contributing to quantitative field resistance to blackleg disease, causal agent Leptosphaeria maculans (Desm.) Ces. Et de Not., in winter rapeseed (Brassica napus L). Theor Appl Genet 96:23-30

Poysa V, Tu JC (1996) Response of cultivars and breeding lines of Lycopersicon spp. to Alternaria solani. Can Plant Dis Surv 76:5-8

Rotem J (1994) The genus Alternaria biology, epidemiology, and pathogenicity, 1st edn. The American Phtyopathological Society, St. Paul, MN, pp 48, 203

Sandbrink JM, Colon LT, Wolters PJCC, Stiekema WJ (2000) Two related genotypes of Solanum microdontum carry different segregating alleles for field resistance to Phytophthora infestans. Mol Breed 6:215-225

Sandbrink JM, Van Ooijen JW, Purimahua C, Vrielink R, Verkerk M, Zabel P, Lindhout P (1995) Localization of genes for bacterial canker resistance in Lycopersicon esculentum using RFLPs. Theor Appl Genet 90:444-450

Sherf AF, MacNab AA (1986) Vegetable diseases and their control. Wiley, New York, pp634-640

Smulders MJM, Bredemeijer G, Rus-Kortekaas W, Arens P, Vosman B (1997) Use of short microsatellites from database sequences to generate polymorphisms among Lycopersicon esculentum cultivars and accessions of other Lycopersicon species. Theor Appl Genet 94:264-272

Stancheva I (1991) Inheritance of the resistance to injuries on the growth mass caused by Alternaria solani in the tomato. Genetika-i-Selektsiya 24:232-236

Stancheva I, Lozanov I, Achkova Z (1991a) Sources of resistance to Alternaria solani in the tomato in wild growing species of the genus Lycopersicon. Genetika-i-Selektsiya 24:126-130

Stancheva I, Lozanov I, Stamova L (1991b) Correlations between the resistance to different injuries from Alternaria solani in the tomatoes. Genetika-i-Selektsiya 24:51-55

Tanksley SD, Ganal MW, Prince JP, de Vicente MC, Bonierbale MW, Broun P, Fulton TM, Giovannoni JJ, Grandillo S, Martin GB, Messegeur R, Miller JC, Miller L, Paterson AH, Pineda O, Roder MS, Wing RA, Wu W, Young ND (1992) High density molecular linkage maps of the tomato and potato genome. Genetics 132:1141-1160

Thirthamalappa, Lohithaswa HC (2000) Genetics of resistance to early blight (Alternaria solani Sorauer) in tomato (Lycopersicum esculentum L.) Euphytica 113:187-193

Van Heusden AW, Koornneef M, Voorrips RE, Bruggemann W, Pet G, Vrielink-van Ginkel R, Chen X, Lindhout P (1999) Three QTLs from Lycopersicon peruvianum confer a high level of resistance to Clavibacter michiganensis ssp. michiganensis. Theor Appl Genet 99:1068-1074

Van Ooijen JW, Boer MP, Jansen RC, Maliepaard C (2002) MapQTL $®$ 4.0, Software for the calculation of QTL positions on genetic maps. Plant Research International, Wageningen, The Netherlands

Van Ooijen JW, Voorrips RE (2001) JoinMap ${ }^{\circledR}$ 3.0, Software for the calculation of genetic linkage maps. Plant Research International, Wageningen, The Netherlands

Veremis JC, van Heusden AW, Roberts PA (1999) Mapping a novel heat-stable resistance to Meloidogyne in Lycopersicon peruvianum. Theor Appl Genet 98:274-280

Vos P, Hogers R, Bleeker M, Reijans M, Van der Lee T, Hornes M, Frijters A, Pot J, Peleman J, Kuiper M, Zabeau M (1995) AFLP: a new technique for DNA fingerprinting. Nucl Acids Res 23:4407-4414

Young ND, Danesh D, Menancio-Hautea, Kumar L (1993) Mapping oligogenic resistance to powdery mildew in mungbean with RFLPs. Theor Appl Genet 87:243-249

Zhang LP, Lin GY, Niño-Liu, Foolad MR (2003) Mapping QTLs conferring early blight (Alternaria solani) resistance in a Lycopersicon esculentum $\times$ L. hirsutum cross by selective genotyping. Mol Breed 12:3-19 